\title{
Drenagem pleural
}

\section{Drainage of pleural fluids}

\author{
Federico Garcia Cipriano, Lycio Umeda Dessote
}

\begin{abstract}
RESUMO
A drenagem pleural é procedimento cirúrgico largamente utilizado na prática médica diária, que permite o restabelecimento das pressões negativas no espaço pleural. Apesar de ser considerado ato relativamente simples, poderá levar à graves complicações devido a falta de cuidados que precisam ser respeitados. Procuramos ressaltar alguns aspectos que, se não respeitados no seu conjunto, acabam determinando o insucesso dos procedimentos de drenagem de tórax.
\end{abstract}

Palavras-chave: Drenagem Pleural. Drenagem/técnicas. Derrame Pleural. Drenagem/métodos.

"Drenagem pleural, um procedimento aparentemente simples deve ser realizado de forma correta, sem as imperfeições comumente observadas". Adib D. Jatene.

A drenagem pleural é um procedimento médico largamente empregado na prática médica diária, em situações eletivas e de emergência. Considerado como ato relativamente simples, poderá levar a severas complicações devido à falta de cuidados que precisam ser respeitados. Como o procedimento é usado em diferentes especialidades médicas, não apenas sua instalação, mas também seu controle são frequentemente, atribuições de não especialistas em cirurgia torácica.

Desta forma, procuramos, de maneira simplificada, ressaltar alguns aspectos que, se não respeitados no seu conjunto, acabam determinando o insucesso dos procedimentos de drenagem de tórax.

\section{Introduçăo}

O fator responsável pela entrada e saída de ar dos pulmões é o gradiente de pressão gerado pela movimentação da caixa torácica. Esse gradiente, transmitido através do espaço pleural (espaço compreendido entre as pleuras parietal e visceral) que mantém sempre uma pressão negativa, faz com que mesmo em repouso os pulmões permaneçam expandidos. $\mathrm{E}$ a pressão pleural que é de $-4 \mathrm{~cm}$ de $\mathrm{H}_{2} \mathrm{O}$ na expiração vai a $-8 \mathrm{~cm}$ de $\mathrm{H}_{2} \mathrm{O}$ na inspiração, em condições normais (Figura 1).

Inúmeras causas como traumas, atos cirúrgicos e doenças pleurais podem provocar acumulo de gás ou líquido na cavidade pleural alterando esse sistema pressórico, determinando colapso pulmonar e insuficiência respiratória de intensidade varável (Figura 2).
1. Docente. Divisão Cirurgia Torácica e Cardiovascular. Departamento de Cirurgia e Anatomia da Faculdade de Medicina de Ribeirão Preto da USP.
Correspondência: Departamento de Cirurgia e Anatomia da FMRP-USP. Hospital das Clínicas da FMRP-USP - 9o andar Avenida Bandeirantes, 3900 14048-900 - Ribeirão Preto/SP

Artigo recebido em 20/07/2010 Aprovado para publicação em 24/02/2011 


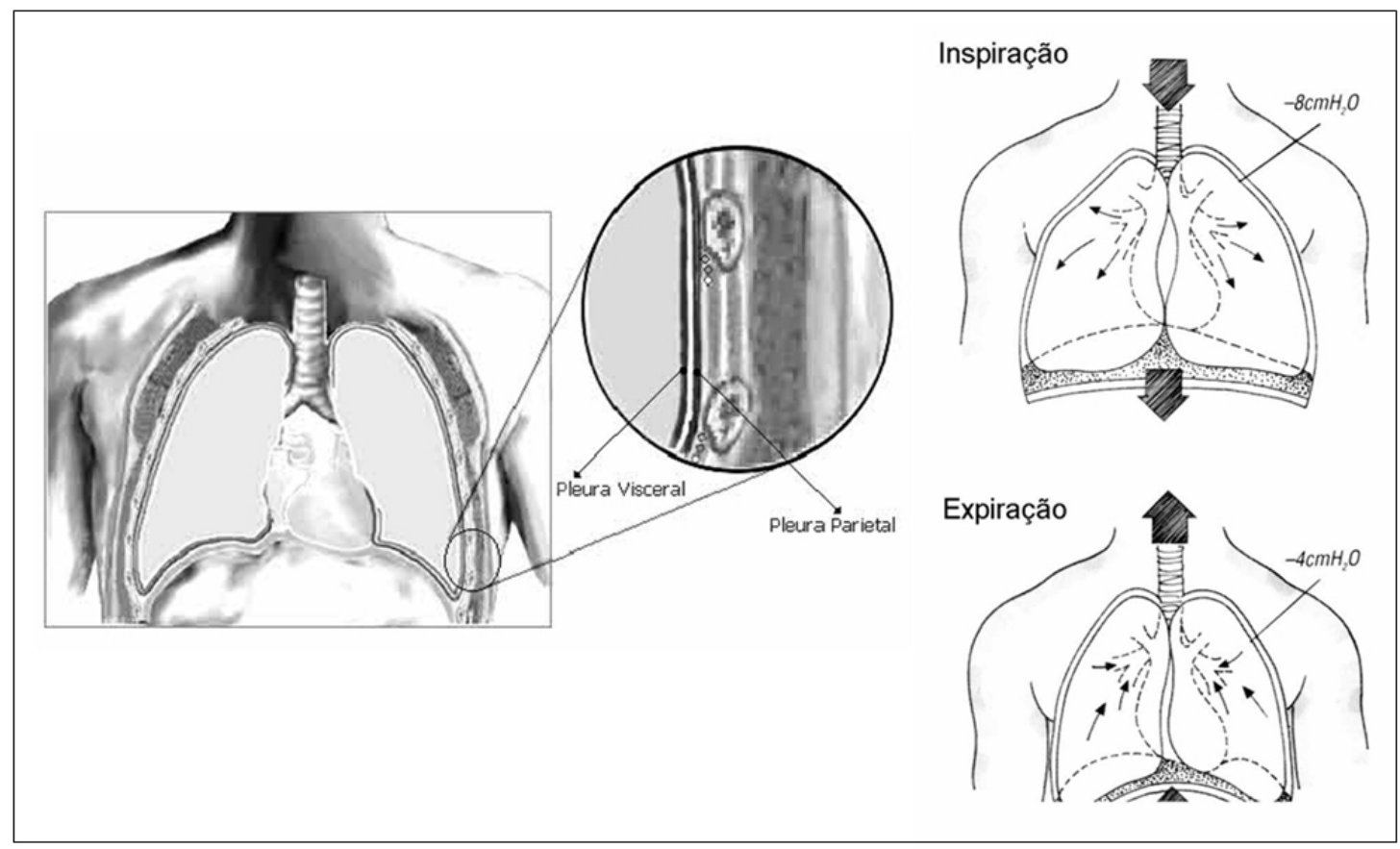

Figura 1: Anatomia da cavidade pleural e pressão intra-pleural

Nessas situações uma drenagem pleural está indicada. Porém, embora seja procedimento rotineiro em hospitais, o que se observa é que os cuidados com os drenos torácicos costumam variar muito, não só de um hospital para outro, como também entre as várias equipes (médica, fisioterápica e de enfermagem) que assistem ao paciente, podendo comprometer o resultado de uma drenagem torácica.

\section{Características Ideais do Sistema de Drenagem Torácica}

Um sistema de drenagem é composto por:

1) dreno de tórax

2) conexões intermediárias e extensões

3) frasco selo de água.
A seguir descrevemos as características ideais desses componentes.

\subsection{Dreno de tórax}

- Tubular multiperfurado pela maior superfície de drenagem e menor chance de obstrução (Figura 4).

- Siliconizado, pois dificulta a aderência de coágulos.

- Consistência firme pela menor chance de colapsar e de formar coágulos; evite drenos rígidos que provocam dor e podem lesar o pulmão.

- Calibre em adultos: 36 F (3/8') em hemotórax ou derrames espessos; 28 F (1/4') em pneumotórax ou derrames fluidos.

- Calibre em crianças: 16 F em recém nascidos; 22 F com 1 ano de idade.

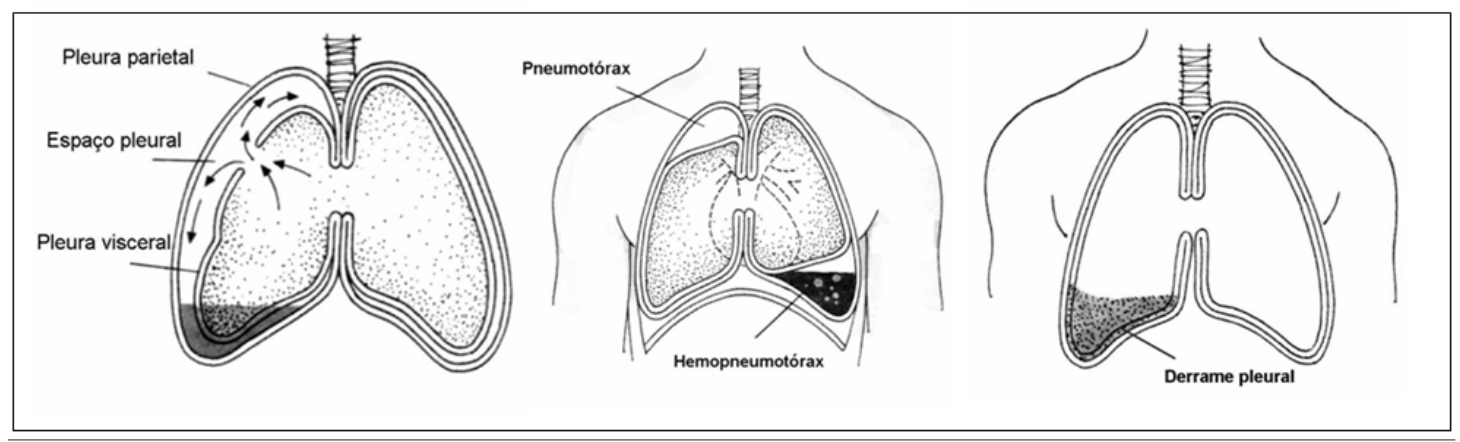

Figura 2: Indicações de drenagem pleural. 


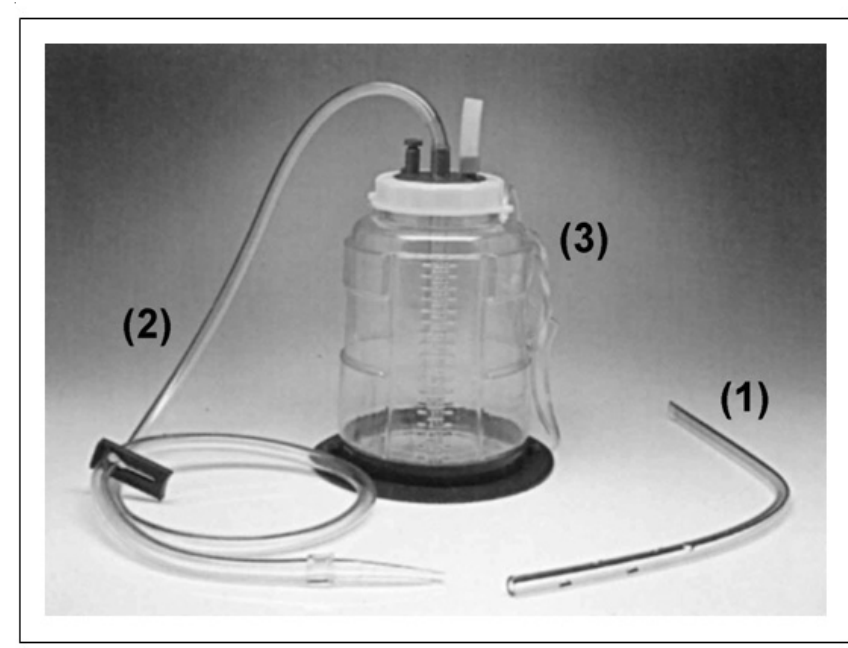

Figura 3 - Sistema de drenagem pleural

- Radiopaco ou com linha radiopaca o que permite confirmar, por radiografia, se a última perfuração do dreno está na cavidade pleural e a sua posição.

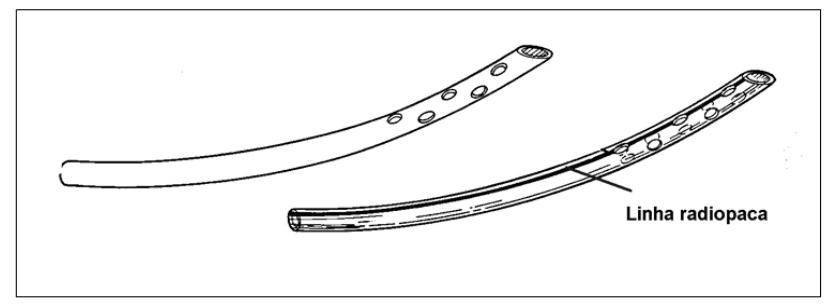

Figura 4: Drenos tubulares multiperfurados.

- Fixação deve ser feita com um ponto de nylon ou algodão na pele, além de fixação adicional por "meso" e "contra-meso" para evitar deslocamentos que alterem a posição do dreno (Figura 5).

\section{Orientações para fixação do dreno pleural:}

- O ponto dado pelo cirurgião logo após a drenagem é amarrado firmemente em torno do dreno e

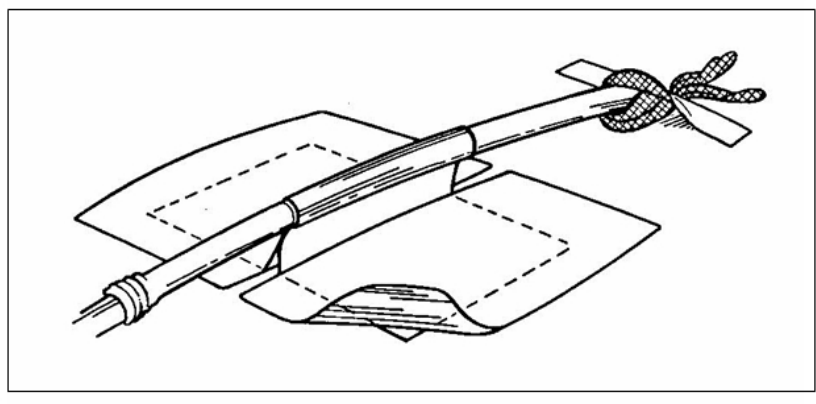

Figura 5: Esquema de fixação do dreno com "meso"e "contrameso". frouxamente à pele, ajudando a fixá-lo no local de sua inserção.

- O "meso" e o "contra-meso" são feitos a seguir e devem permanecer enquanto permanecer o dreno, sendo refeitos sempre que necessário. Eles auxiliam na fixação, reduzindo a dor e risco de saída acidental do dreno. Para fazer o "meso" e "contra-meso" recorte uma tira de $20 \mathrm{~cm}$ e duas tiras de $10 \mathrm{~cm}$ de comprimento de fita adesiva hospitalar de $5 \mathrm{~cm}$ de largura (micropore ou esparadrapo). Envolva o dreno na metade da fita longa $(20 \mathrm{~cm})$, e colando fita com fita por $2 \mathrm{~cm}$ abaixo do dreno. Fixe o restante da fita adesiva na pele. Faça o "contra-meso" afixando as fitas menores $(10 \mathrm{~cm})$ sobre cada lado do "meso", paralelamente ao dreno (Figura 5).

- Posicione adequadamente o dreno em relação ao corpo do paciente evitando dobras em relação ao seu maior eixo. Evite fixações na região do quadril, pois a movimentação do doente pode provocar angulações no dreno.

- A fixação do dreno depende muito mais do "meso" e "contra-meso" do que do ponto na pele.

\subsection{Conexão intermediária e extensão}

- Conector (intermediário) entre o dreno e a extensão, preferencialmente de plástico transparente e de calibre compatível. Conectores ou extensões de calibre reduzido não dão boa vazão ao fluxo de ar em fístulas aéreas de alto débito e se obstruem facilmente por coágulos (Em tempo: fístula aérea decorre das roturas de brônquios ou de bolhas de enfisema que mantém um escape constante de ar para a cavidade pleural). Use fita adesiva hospitalar para fixar a conexão. (Figura 6)

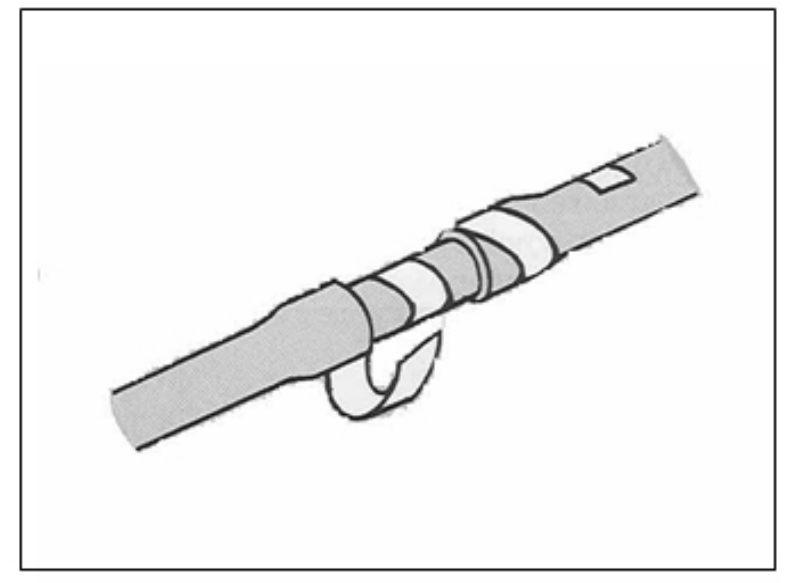

Figura 6: Conexão dreno-extensão fixada com fita adesiva hospitalar em espiral. 
- Extensão de látex ou plástico transparente (com diâmetro interno mínimo de $0,95 \mathrm{~mm}$ ) permite a visualização da coluna líquida no seu interior. Evite extensões reesterilizadas e que perdem a consistência e colabam naturalmente ou com a aspiração do sistema. O comprimento da extensão deve ser suficiente para permitir a mudança de decúbito do paciente, mas na muito longa, evitando a formação de alças que podem criar colunas hidrostáticas dificultando a drenagem.

\subsection{0 frasco selo de água (Figura 7)}

- Frasco de vidro ou plástico transparente e graduado para permitir o controle do volume drenado.

- Conexão e respiro de calibre adequados: pacientes com fístulas podem ter fluxo aéreo alto principalmente durante a tosse ou ventilação mecânica.

- Nível líquido é o mecanismo que funciona como válvula no sistema de drenagem, cobrindo os $2 \mathrm{~cm}$ distais do tubo do frasco selo de água. Esse mecanismo permite a drenagem do líquido ou gás e impede a entrada de ar na cavidade pleural. Entretanto se o tubo estiver mergulhado mais que $2 \mathrm{~cm}$, a drenagem aérea acaba sendo prejudicada porque aumenta a resistência ao fluxo de drenagem.

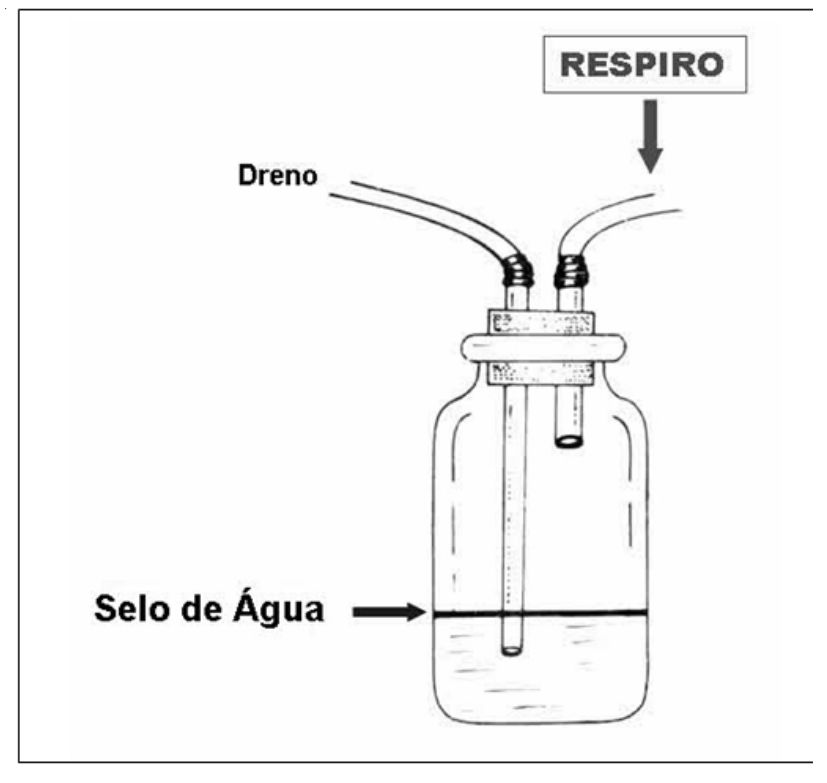

Figura 7: Frasco selo de água.

\section{Aspiração do Sistema}

A aspiração aplicada ao respiro do frasco selo de água anula a pressão atmosférica e produz pres- são negativa no frasco facilitando a drenagem. Sua indicação é formal nos casos de drenagem sem expansão pulmonar completa, geralmente quando há grandes fístulas aéreas.

A aspiração do sistema de drenagem pode ser feita com frasco de aspiração, tubo regulador de vácuo ou sistema de alto fluxo.

\subsection{Frasco de aspiração}

A pressão negativa aplicada será determinada pelo comprimento do tubo regulador de pressão que estiver mergulhado no líquido. Se o tubo estiver mergulhado $20 \mathrm{~cm}$ no líquido, a pressão será de $-20 \mathrm{~cm}$ H2O. (Figura 8).

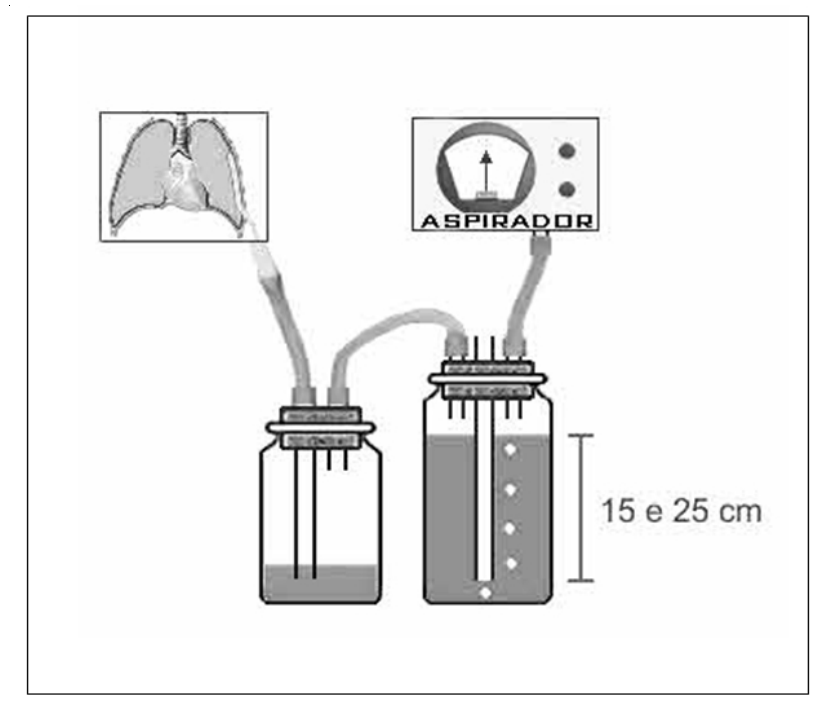

Figura 8: Sistema de aspiração com dois frascos.

\subsection{Tubo regulador do vácuo}

Mesmo princípio de funcionamento do frasco de aspiração (Figura 9).

Esses dois sistemas têm o inconveniente de serem sistemas de baixo fluxo, independente da pressão negativa que está sendo empregada. Além disto, podem bloquear o sistema se houver diminuição ou interrupção do vácuo.

Importante: o frasco de aspiração ou o tubo regulador de vácuo devem manter um borbulhamento constante enquanto estão sendo aspirados. A parada do borbulhamento , durante a tosse ou expiração forçada, significa que o débito aéreo da drenagem é maior que a capacidade de vazão de fluxo do sistema. 


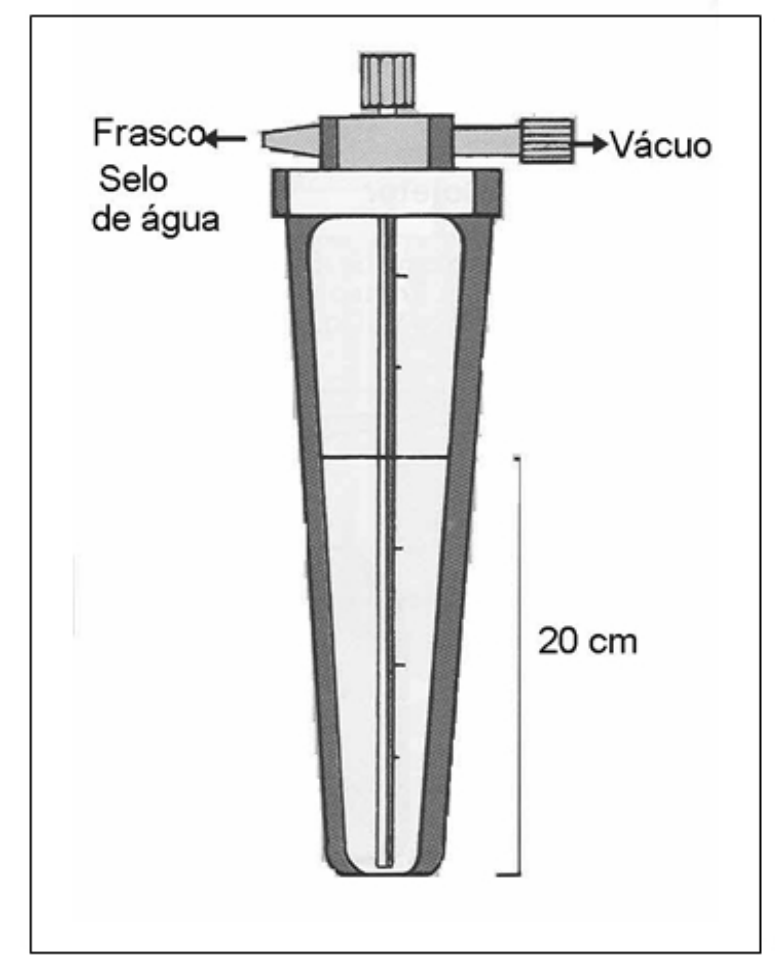

Figura 9: Tubo regulador de vácuo.

\subsection{Aspirador de alto fluxo}

É o melhor sistema de aspiração com nível de pressão facilmente regulável, não bloqueia o sistema mesmo se o aparelho estiver desligado, porém não disponíveis em nosso meio além do custo elevado (Figura 10).

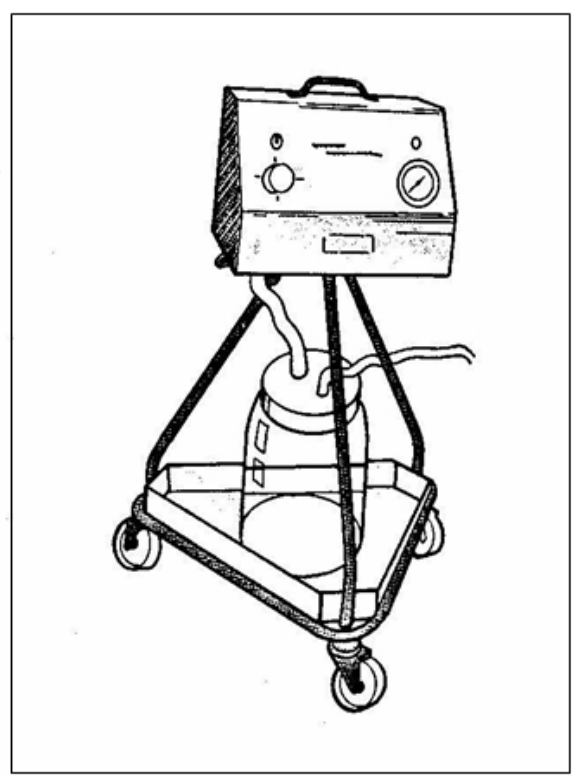

Figura 10: Aspirador de alto fluxo
Observação: o importante num sistema de aspiração não é o nível de pressão negativa empregada, mas sim o fluxo que o sistema alcança. Mantenha a pressão de aspiração entre -10 a $-20 \mathrm{~cm} \mathrm{H} 2 \mathrm{O}$ para crianças e -20 a $-30 \mathrm{~cm} \mathrm{H} 2 \mathrm{O}$ para adultos. Procure utilizar sistemas de aspiração com alto fluxo de drenagem.

\section{Recursos Alternativos do Siste- ma de Drenagem}

Embora se consiga resolver a maior parte dos casos de drenagem torácica apenas com o uso do frasco selo de água e do frasco de aspiração, existem outros recursos que podem ser úteis em situações especiais.

\subsection{Frasco Coletor}

Quando o volume de drenagem for alto pode ser utilizado um frasco coletor, que pode ser um compartimento isolado, evita a necessidade de esvaziar constantemente o nível do líquido do frasco selo de água. Todavia, lembre-se que o frasco coletor aumenta o espaço morto do sistema funcionando como uma extensão do espaço pleural do paciente. Por isso sempre que usar um frasco coletor utilize um esquema de aspiração associado ao sistema (Figura 11).

4.2. Sistemas industrializados combinados que funcionam baseados no princípio clássico de drenagem, e que incorporam na mesma unidade o frasco coletor, o frasco selo de água e o frasco de aspiração.

Apesar de funcionarem interligados, suas 3 câmaras são independentes, facilitando seu manuseio e fazendo com que o volume de drenagem não interfira com o nível líquido do no frasco selo de água. Sua desvantagem é o alto custo e o fato de não ser produzido em nosso meio (Figura 12).

\section{Cuidados com o sistema}

\subsection{Curativo diário}

Deve ser mantido sempre limpo e seco em torno do dreno. Use uma gaze dobrada em triângulo envolvendo o dreno junto à incisão cutânea e fixada na fita adesiva. Drenagem peritubular pode significar infecção no trajeto do dreno, obstrução do sistema ou um orifício do dreno na parede torácica. (Figura 13). 


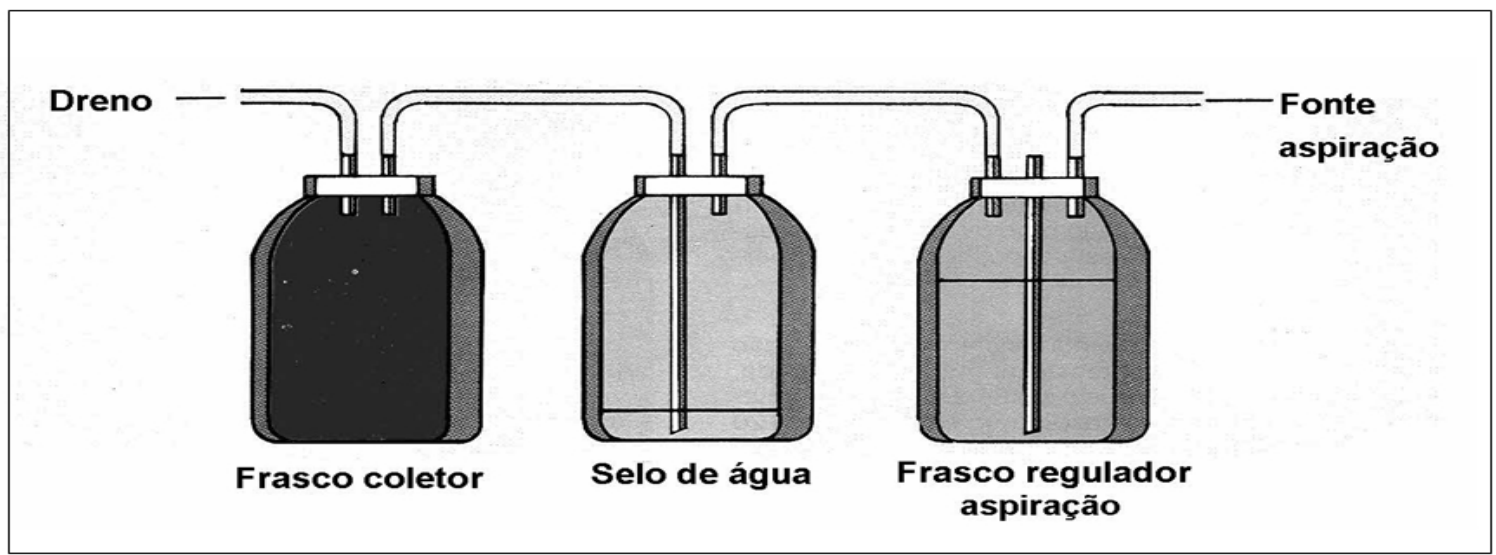

Figura 11: Sistema de aspiração com 3 frascos.

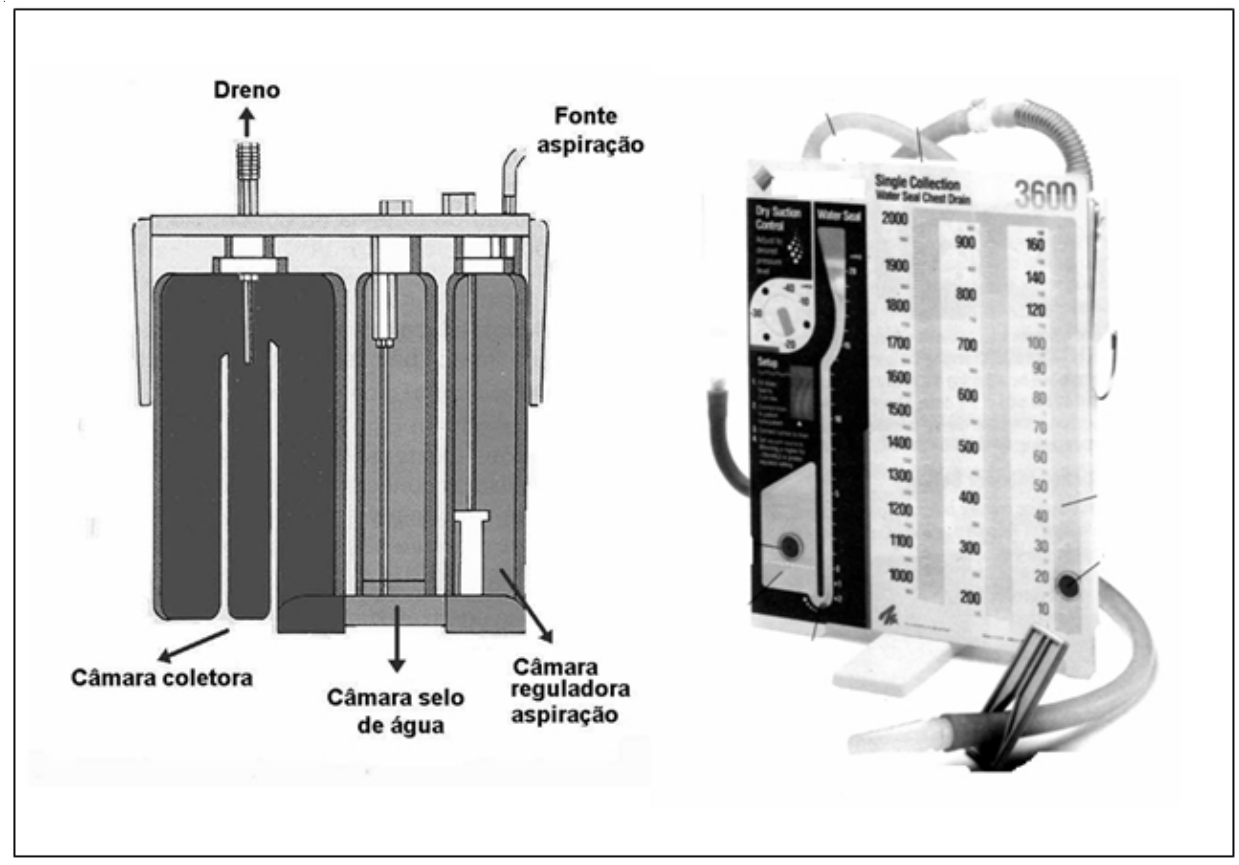

Figura 12: Sistemas industrializados combinados

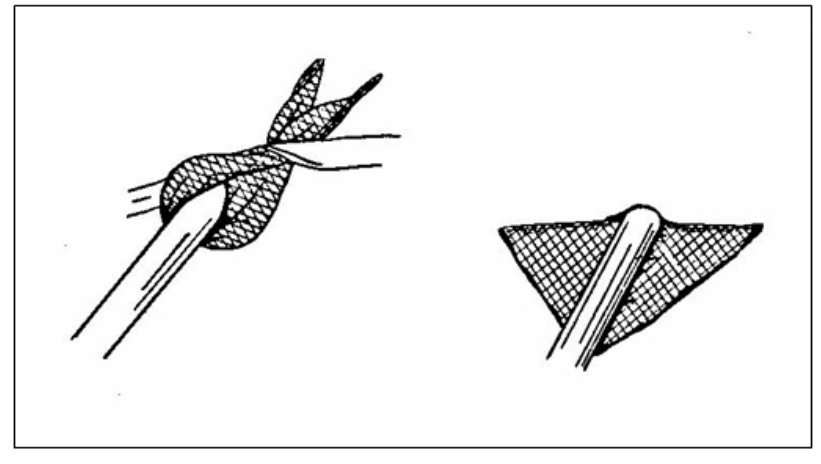

\subsection{Fixação}

Refaça o "meso" se necessário e confira o ponto de fixação. Lembre-se, um "meso" bem feito evita saídas acidentais do dreno.

\subsection{Conexões e extensões}

Verifique se não há coágulos; fixe os conectores com fita aplicada em espiral de tal forma que você consiga ver os pontos de conexão, que são os mais propensos a reter coágulos.

Figura 13 - Curativo de inserção do dreno torácico 


\subsection{Nível líquido do selo de água}

Mantendo-o de forma que o tubo fique mergulhado $2 \mathrm{~cm}$ no líquido. Se houver muita drenagem você terá que esvaziar constantemente o frasco selo de água (ou usar o frasco coletor). Troque o líquido do frasco selo de água ao menos uma vez ao dia: pince o dreno o tempo mínimo necessário, desconecte a tampa do frasco, esvazie e anote o volume drenado, e reponha o nível líquido do frasco com água destilada ou soro fisiológico. Cuide para não contaminar o sistema.

\subsection{Controle da drenagem}

- anote rigorosamente qual o volume drenado por unidade de tempo (Ex.: $250 \mathrm{ml} / 6 \mathrm{~h}$ ). Para isso, utilize a fita adesiva junto a escala do frasco selo de água. Marque o dia e a hora da troca do líquido de drenagem. Trocando o líquido, troque também a fita adesiva pois marcas sobrepostas prejudicam um controle adequado.

- anote o aspecto do líquido drenado: amarelo citrino, sangue, pus, quilo.

- anote se existe fístula aérea (borbulhamento no frasco selo de água).

\subsection{Evitar alças na extensão do sistema}

Pois elas dificultam a drenagem do ar.

\subsection{Evitar formação de bolhas}

Coloque 10 gotas de silicone líquido ou álcool no frasco selo de água para evitar a formação de bolhas que podem esgotar o líquido do selo de água por evaporação e produzir pneumotórax ou subir no aspirador, danificando-o.

\subsection{Localização do dreno}

Verifique na radiografia de tórax se não houve deslocamento e confirme se o último orifício do dreno permanece na cavidade pleural. Drenos deslocados, com o último orifício na parede torácica podem causar pneumotórax ou enfisema subcutâneo. Quando excessivamente introduzidos podem provocar dor referida no ombro. Drenos angulados podem comprometer a drenagem e provocar dor ou soluços por estímulos no diafragma.

\subsection{Vazamento no sistema}

Borbulhamentos no frasco selo de água podem ser devidos a:

- fístula aérea;
- drenos mal posicionados;

- vazamento no sistema.

Para excluir vazamentos conecte um sistema de aspiração no respiro do frasco selo de água. A seguir pince o dreno próximo à parede torácica. Se para de borbulhar, trata-se de fístula aérea. Se persistir borbulhando significa que há entrada de ar em algum local do sistema. Cheque as extensões e conexões. Se necessário, troque o sistema.

\section{O que deve ser feito:}

A saída acidental de um dreno de tórax nunca deveria ocorrer. Por isso é fundamental que o mesmo esteja bem feito.

\subsection{Se ocorre saída acidental do dreno em paciente que não tem fístula aérea:}

- Ocluir RAPIDAMENTE o orifício do dreno; não fique esperando material de curativo, use o que tiver às mãos (lençol, toalha, etc.) ou simplesmente aproxime as bordas do orifício com os dedos;

- Avisar o médico responsável;

- Fazer curativo compressivo;

- Não deixe o paciente sozinho; procure tranqüilizalo;

- Administrar O2 se o paciente apresentar desconforto respiratório;

- Se o paciente piorar descomprima o orifício; na dúvida é preferível um pneumotórax total a um pneumotórax hipertensivo.

\subsection{Se ocorre saída acidental do dreno em paciente que tem fístula aérea:}

- Ocluir o orifício do dreno na inspiração e abrir na expiração; a oclusão continua provoca um pneumotórax hipertensivo que pode levar a balanço de mediastino e parada cardíaca;

- Avisar o médico responsável rapidamente;

- Preparar material para drenagem de emergência.

\subsection{Se o paciente apresentar enfisema sub- cutâneo após a drenagem:}

- Afastar hipótese de obstrução do sistema;

- Checar se o último furo do dreno não está fora da cavidade pleural;

- Avaliar se o dreno consegue dar vazão ao fluxo de fuga aérea da fístula. 
- Ocasionalmente são necessários dois drenos e aspiração do sistema em pacientes com fístula aérea de alto débito.

\subsection{Se o dreno borbulhar excessivamente? Você tem três possibilidades:}

- ser uma fístula aérea de alto débito; certifique-se que o médico responsável pelo paciente esteja ciente;

- o último furo do dreno está fora da cavidade pleural; uma radiografia de tórax pode esclarecer, se tiver sido utilizado dreno com linha radiopaca com o último furo feito sobre a linha;

- haver perfuração ou vazamento nas conexões ao longo do sistema de drenagem.

\subsection{Se a coluna líquida do dreno parar de os- cilar? Verifique se:}

- o sistema está ocluido;

- trata-se de dreno mediastinal: em geral drenos no mediastino oscilam pouco com a respiração e mais com os batimentos cardíacos;

- o paciente encontra-se sob ventilação mecânica: nesses casos o paciente respira pela pressão positiva do aparelho e não por "aumento" na pressão negativa do espaço pleural;

- o pulmão está totalmente expandido: quando isso ocorre as pleuras parietal e visceral se acolam tornando virtual o espaço e diminuindo a pressão negativa intrapleural fazendo a coluna líquida do dreno parar de oscilar.

Observação: Num dreno intrapleural a coluna líquida oscila para cima na inspiração e para baixo na expiração; oscilação em sentido inverso significa que o dreno deve ter sido colocado inadvertidamente na cavidade abdominal.

\section{Retirada do dreno}

Critérios para retirada de um dreno pleural:

- a radiografia de tórax mostrar que o pulmão está completamente expandido;

- o volume da drenagem for pequeno (entre 50 a $100 \mathrm{ml} \mathrm{em} \mathrm{24h);}$

- aspecto claro (seroso) do volume drenado;

- o dreno não borbulhar a pelo menos $24 \mathrm{~h}$.

\section{O que deve ser evitado}

- Evite clampear o dreno no transporte do paciente.

- Evite ordenhar o dreno, pois esse procedimento é pouco efetivo e pode gerar uma pressão negativa muito alta (com exceção dos drenos mediastinais). Quando necessitar desobstruir o sistema, desconecte a extensão, e introduza uma sonda nasogástrica calibrosa pelo dreno, aspirando intermitentemente. Notado que o dreno está pérvio, retire rapidamente a sonda e clampe o dreno até conectar novamente a extensão do selo de água. Lembre-se de retirar o clampe do dreno. Tome todos os cuidados de antissepsia para esse procedimento.

\section{0 que nunca deve ser felto}

- Nunca eleve o frasco selo de água ao nível do tórax do paciente pois o líquido drenado irá refluir para a cavidade pleural.

- Nunca desligue uma aspiração sem antes desconectar o sistema de aspiração do respiro do frasco selo de água.

- Nunca clampeie um dreno que estiver borbulhando quando for trocar ou elevar o frasco, se possível use apenas os dedos para pinçar a extenção. Lembre-se: um dreno clampeado pode provocar um pneumotórax hipertensivo, com balanço do mediastino e parada cardíaca (Figura 14).

- Nunca conecte a rede de vácuo direto no respiro do frasco selo de água, use sempre um sistema regulador (frasco de aspiração ou tubo regulador de vácuo).

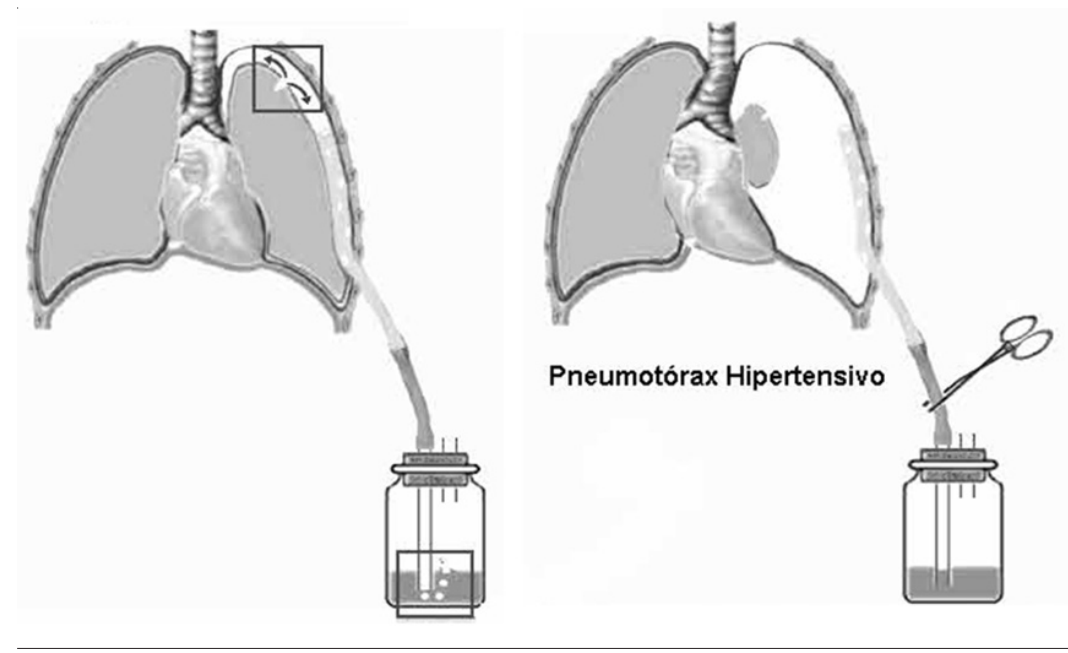

Figura 14: Pneumotórax hipertesivo provocado por clampamento de dreno borbulhando. 


\section{ABSTRACT}

Drainage of pleural fluids, which allows for the reestablishment of negative pressures in the pleural space, is widely employed in routine medical practice. Despite being considered a relatively simple act, it may lead to severe complications if adequate care is not taken. We will highlight some aspects which, if not well tended to, will result in unsuccessful outcome of chest drainage procedures.

Keywords: Pleural Drainage. Drainage/techniques. Pleural Effusion. Drainage/methods.

\section{Bibliografia recomendada}

1. Miller KS, Sahn SA. Chest Tubes - Indications, Technique, Management and Complications. Chest 1987;91:258-64

2. Munnell ER. Thoracic Drainage. Ann Thorac Surg 1997;63:1497502

3. Perfeito JAJ. Técnicas cirúrgicas de pleurodese nas afecções pleurais - Punção e drenagem pleural. In: Cukier, A.; Nakatani, J.; Morroni, N. - Pneumologia: atualizaçao e reciclagem. São Paulo, Atheneu, 1997. p.609-15.

4. Perfeito JAJ, Crotti PLR, Succi JE, Leão LEV. Procedimentos de urgência em cirurgia torácica. In: Burihan E. Emergências em cirurgia. São Paulo, Sarvier, 1995. p.125-36. 